\title{
Cartografía del tsunami inmobiliario: el movimiento urbano popular y los vínculos urbano-rurales del boom inmobiliario en la ciudad de México
}

\section{Cartography of the real-estate tsunami: urban social movements and the rural-urban linkages of the real state boom of Mexico City}

\author{
Adrián Flores \\ Universidad Anáhuac, México / UGI-LATAM \\ adrian.floresr@anahuac.mx
}

\begin{abstract}
RESUMEN
La Ciudad de México constituye una vasta concentración de fuerza de trabajo y medios de producción que representa una formidable capacidad de extracción de ganancias, y requiere de una compleja gestión para su control. En los últimos años, la batalla por la metrópoli se ha agudizado y actualmente se expresa en la expansión de desarrollos inmobiliarios, a la que el movimiento urbano popular denomina el tsnunami inmobiliario. Esto es la densificación del núcleo urbano, a partir de la expansión vertical de la ciudad mediante la construcción de torres de vivienda, pero también mediante la expansión de nuevas redes de transporte y la sobreposición de vialidades de acceso controlado, la expansión de centros comerciales, la privatización de los espacios públicos, la eliminación de los espacios no construidos, el desplazamiento de la población más pobre de los núcleos urbanos a partir de despojos y desalojos violentos, y su reemplazo con hacinamientos verticales de población endeudada a largo plazo con la industria inmobiliaria. Para comprender esta nueva fase de expansión urbana, se realiza una cartografía del tsunami inmobiliario a partir de cinco oleadas de urbanización e industrialización, bajo el supuesto de que visibilizar la coordinación de las estrategias empresariales y estatales de apropiación del suelo urbano, permite comprender y fundamentalmente fortalecer a los movimientos urbano populares.
\end{abstract}

Palabras clave: Tsunami inmobiliario; boom inmobiliario; movimiento urbano popular; Ciudad de México.

\section{Citar como:}

Flores, A. (2019). Cartografía del tsunami inmobiliario: el movimiento urbano popular y los vínculos urbano-rurales del boom inmobiliario en la ciudad de México. Espiral, revista de geografías y ciencias sociales, 1(1), 007 - 028. http://dx.doi. org/10.15381/espiral.v1i1.15843 


\begin{abstract}
Mexico City is one of the oldest and largest urban concentrations in the world. It constitutes a vast concentration of labor power and means of production that represents a formidable capacity for extracting profits, and requires a complex management for its control. In recent years the battle for the metropolis has become more acute and is currently expressed in the expansion of real estate developments, named by popular urban movement as the real estate tsunami. This is the densification of the urban core from the vertical expansion of the city through the construction of housing towers, but also through the expansion of new transport networks such as MetroBus (Bus Rapid Transport) and the overlap of controlled access roads, the expansion of shopping centers, the privatization of public spaces (pocket parks), the elimination of unbuilt spaces, the displacement of the poorest population of urban centers from violent dispossessions and evictions and its replacement with vertical overcrowding of a long-term indebted population with the real estate industry. To understand this new phase of urban expansion, a cartography of this real estate tsunami is carried out, under the assumption that making visible the coordination of business and state strategies of appropriation of urban land, allows to understand and fundamentally strengthen the popular urban movements.
\end{abstract}

Keywords: Real-estate boom; popular urban movement; Mexico City.

\title{
1. Introducción. El tsunami inmobiliario en la Ciudad de México
}

La Ciudad de México fue fundada en 1321 sobre el lago de Texcoco y actualmente es la cuarta concentración urbana más poblada (después de Tokyo, Delhi y Shanghai),

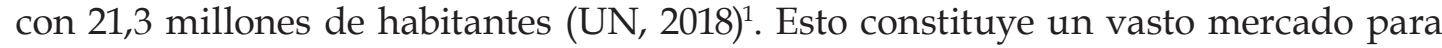
bienes de consumo, desde viviendas, automóviles y alimentos, hasta espectáculos y drogas; un enorme botín político del que es posible extraer una ingente cantidad de recursos vía impuestos y, principalmente, una excepcional concentración de fuerza de trabajo y medios de producción. Todo esto representa una formidable capacidad de extracción de ganancias que requiere, a su vez, una intrincada gestión para el control de la riqueza social y natural de toda la cuenca del valle de México.

A lo largo de siglos, múltiples grupos han disputado el control de la Ciudad de México, pero en los últimos años la batalla por la metrópoli se ha agudizado. Es probable que las crisis seculares del capitalismo desaten periódicamente la voracidad de distintos grupos empresariales por apoderarse del suelo urbano, de maneras siempre novedosas. También es probable que la crisis inmobiliaria de 2008 sea la coyuntura que define el carácter que asume actualmente la expansión inmobiliaria en la Ciudad de México. De igual forma, las transformaciones neoliberales que iniciaron en México en $1982^{2}$, así como la transición democrática que comienza en $1988^{3}$, han modificado las estrategias de los grupos políticos para gestionar el crecimiento urbano.

Sin embargo, más allá de la lógica de poder capitalista desplegada por las empresas y de la lógica de poder territorial emprendida por el Estado (Arrighi, 1999), se considera que son los movimientos urbano populares los que permiten comprender en términos integrales el estado de la disputa contemporánea por la Ciudad de México. A lo largo de los años, al haber resistido simultáneamente frente a las estrategias moleculares $\mathrm{y}$ territoriales de empresas y gobiernos, a veces coordinadas y a veces divergentes, los movimientos urbanos populares marcan los periodos, los ritmos, los lugares y las formas que asumen tales estrategias. Esto no implica que para comprender las estrategias empresariales y estatales sea necesario mapear a los movimientos urbanos;

1 De acuerdo con la Revisión de las Perspectivas de Urbanización Mundial de 2018, realizada por la ONU, en 2020 Sao Paolo tendrá 22 millones de habitantes y se colocará por encima de la Ciudad de México, que alcanzará 21,782 millones de habitantes.

2 En 1982, el gobierno mexicano se declaró insolvente para atender las deudas con sus acreedores internacionales, principalmente bancos ingleses y estadounidenses. La "crisis de la deuda" de 1982 se resolvió mediante préstamos de los organismos financieros internacionales a cambio de emprender Programas de Ajuste Estructural (PAE)

3 En 1988 se registra el primer fraude electoral para evitar que un gobierno progresista asumiera el control político a nivel federal. A cambio de mantener la disputa política en el terreno electoral, se otorgó al grupo político disidente el control político sobre la capital del país, el Distrito Federal. Desde 1997, esta izquierda institucional gobierna sobre esta entidad política, ahora denominada Ciudad de México.

008 | Espiral 1(1): 008 - 028 
al contrario, realizar la cartografía de las estrategias empresariales y estatales es lo que permite comprender y fundamentalmente fortalecer a los movimientos urbano populares.

Este ejercicio cartográfico considera que el heterogéneo y complejo movimiento urbano popular que persiste en la Ciudad de México, enfrenta actualmente y de múltiples formas una fase más de la expansión urbana a la que se denomina el tsunami inmobiliario. Esto es la densificación del núcleo urbano a partir de la expansión vertical de la ciudad mediante la construcción de torres de vivienda y oficinas, facilitada por la densificación de una nueva red de transporte público (particularmente el MetroBús, tomado del modelo Bus Rapid Transport) y la sobreposición de vialidades de acceso controlado (autopistas urbanas y segundos pisos). Sumado a lo anterior, se observa la expansión de centros comerciales, la reducción y privatización de los espacios públicos a partir del concepto de parque de bolsillo, la eliminación de los espacios abiertos o no construidos mediante una estrategia de apropiación de la reserva territorial. Toda esta inversión en infraestructura se expresa en el desplazamiento de la población de los barrios enclavados en los principales núcleos urbanos, a partir de despojos y desalojos violentos, y su reemplazo con hacinamientos verticales de población endeudada a largo plazo con la industria inmobiliaria ${ }^{4}$.

Para ubicar al tsunami inmobiliario como parte de un proceso espacial imbricado en relaciones urbano-rurales más amplias, y trascender la concepción de la transformación urbana como un fenómeno limitado a barrios selectos del núcleo urbano -como generalmente ocurre con el concepto de gentrificación (Janoshka y Sequera, 2014)- se propone, a modo de hipótesis, una conceptualización cartográfica del crecimiento urbano de la Ciudad de México a partir de cuatro ciclos de expansión urbana e industrial. Los ciclos se encuentran articulados por la expansión y uso de una infraestructura de transporte, a lo largo de los cuales se han constituido los diversos sectores populares (desposeídos, ejidatarios, obreros, migrantes, colonos, vecinos) que componen el complejo y heterogéneo movimiento urbano popular que actualmente enfrenta, una vez más, una nueva fase de expansión inmobiliaria.

Cuatro ciclos anteceden al tsunami inmobiliario. El primer ciclo de expansión urbana e industrial (1876-1915) corresponde a la articulación del valle y la Ciudad de México mediante la red de ferrocarriles impulsada por el gobierno oligárquico liberal del dictador Porfirio Díaz (1876-1911). El segundo ciclo (1915-1940) se caracteriza por la articulación entre la red ferroviaria del periodo anterior y el reparto de tierras impulsado por los primeros gobiernos revolucionarios. El tercer ciclo (1940-1970) articula el proyecto de industrialización y urbanización, comandada por los gobiernos nacionalistas posrevolucionarios, mediante una nueva red de infraestructura de transporte centrada en los hidrocarburos. El cuarto ciclo (1970-2000) corresponde a la crisis de la industrialización nacionalista y la adecuación de la expansión urbana al nuevo papel del Estado asumido por los gobiernos neoliberales.

Finalmente, se presenta el último ciclo de expansión urbana (2000-2018) como una urbanización salvaje (Barreda, 2009), caracterizada por la alianza entre distintas empresas inmobiliarias y funcionarios de los gobiernos locales, unidos para facilitar la apropiación capitalista del suelo urbano. Las alianzas público-privadas no son nuevas en México, sino que tuvieron un desarrollo progresivo desde inicio del siglo XXI. Así, en la primera fase (2000-2008), la alianza con presidentes municipales se expresa particularmente en la expansión urbana horizontal hacia las periferias del Estado de México; mientras que durante la segunda fase (2008-2018), se consolidan distintas alianzas con funcionarios de la asamblea legislativa, las delegaciones políticas y la jefatura de gobierno del Distrito Federal (Ciudad de México), motivados por articular

4 No se trata siempre y únicamente del reemplazo de población de bajos ingresos por población de ingresos medios o altos. Además de cuestiones de clase (gentrificación) y raza (blanqueamiento), el proceso incluye, al menos, un tercer factor: el desplazamiento de adultos mayores, muchas veces pensionados, y la llegada de jóvenes sin derechos laborales. 
la expansión vertical desde el núcleo urbano hacia el resto de la ciudad. Ambas fases son acompañadas de grandes inversiones en infraestructura de transporte que delinean el contorno del verdadero megaproyecto urbano: la conformación de la megalópolis de la Ciudad de México.

El tsunami inmobiliario es una metáfora, empleada por vecinos organizados de las colonias Juárez y San Rafael, para describir la ola expansiva de torres de oficinas, de viviendas y de plazas comerciales que amenazan la prevalescencia de los actuales habitantes de las zonas centrales de la ciudad frente al proceso de blanqueamiento ${ }^{5}$; pero además, permite describir los temblores y la sensación de avasallamiento que se experimenta en los barrios aledaños a la perforación de excavaciones profundas para la construcción de grandes torres. El tsunami inmobiliario es un concepto que persigue la articulación de la diversidad de resistencias emplazadas por los distintos sectores del movimiento urbano popular, conformados durante los cuatro ciclos previos, frente a un mismo megaproyecto de ciudad impulsado por una alianza entre el capital inmobiliario y los gobiernos locales de la Ciudad de México.

\section{El porfiriato y la Revolución Mexicana: 1876-1915}

Al iniciar el siglo XX, más del 90\% de la población de México vivía en el campo. Desde 1880 hasta 1900, la Ciudad de México mantuvo su población en alrededor de 340 mil habitantes (INEGI, 1994), mientras que en el mismo periodo, los pueblos y comunidades que le rodeaban duplicaron su población, alcanzando los $200 \mathrm{mil}^{6}$. Entre 1876 y 1911, México fue gobernado por una oligarquía liberal representada por Porfirio Díaz, cuya dictadura se caracterizó por la apertura del país a la inversión extranjera. Los capitales fueron direccionados a sectores estratégicos (minería, petróleo, ferrocarriles y agricultura de exportación de henequén, hule, garbanzo, café, ixtle y maderas preciosas) y hubo una intensa política de concentración de la propiedad de la tierra: antes de iniciar la Revolución Mexicana, 20\% del territorio nacional era propiedad de tan sólo 50 familias (Macías y Pérez, 2015) 7 .

Como se puede ver en los mapas que componen esta cartografía del tsunami inmobiliario, se destacan cuatro elementos generales: 1) el tamaño de la Ciudad de México respecto del valle de México; 2) la cantidad de población de la ciudad y del valle de México mostradas en los recuadros; 3 ) la lógica espacial de la infraestructura de transporte, es decir, los puntos que conecta; y 4) el estado general que guardan de la tierra y el agua. El mapa 1 destaca particularmente algunos de los terrenos de las haciendas del Distrito Federal y los cascos de algunas haciendas y ranchos del Estado de México al iniciar la Revolución Mexicana; de igual forma destaca la interconexión de la Ciudad de México mediante la red de ferrocarriles que comunicaban al valle de México con los puertos de Veracruz (al oriente) y Acapulco (al sur) y las ciudades de Toluca (al poniente), Querétaro y Pachuca (al norte), y finalmente, el tamaño de los cuerpos de agua que conformaban aún al gran Lago de Texcoco.

Aunque el porfiriato logró integrar el territorio nacional mediante la expansión de la red de ferrocarriles, que pasó de 617 km a $19.748 \mathrm{~km}$ (INEGI, 2009) ${ }^{8}$, y sentó las bases para la producción industrial del país (aunque solo de productos como alcohol, azúcar,

\footnotetext{
5 El tsunami inmobiliario, el blanqueamiento por despojo y la prevalescencia es la triada de conceptos que desde el movimiento urbano-barrial de la colonia Juárez se utilizan para enfrentar los procesos metropolitanos contemporáneos a una escala vecino-barrial: ante el blanqueamiento generado por el tsunami se opone el proyecto de prevalescencia de los vecinos en el barrio. Ver las notas del Dr. Pablo Gaytán en http://rupturacolectiva.com/tag/blanqueamiento-por-despojo/ 6 La cifra exacta es 196.795; el cálculo se realiza a partir de la diferencia entre 541 mil habitantes en el Distrito Federal, en 1900, y los 344 mil habitantes de la Ciudad de México, de acuerdo con los datos de las Estadísticas Sociales del Porfiriato (Secretaría de Economía, 1954).

7 Al parecer, el dato tiene su origen en Gutelman, Michel (1974) Capitalismo y Reforma Agraria en México, México: ERA, pp. 35-36, y es citado por diversas fuentes, v.gr., Durand Alcántara, Carlos Humberto, (2009) El derecho agrario y el problema agrario en México (su proyección histórico-social), México: Editorial Porrúa.

8 Con base en Fuentes, Díaz (1951) El problema ferrocarrilero en México y en Sergio Ortíz Hernández (1970) Los ferrocarriles en México, Dirección General de Ferrocarriles en Operación, México: SCT, Gustavo Garza (1985) registra un aumento de 666 en 1876 a $19.280 \mathrm{~km}$ en 1910.
}

010 | Espiral 1(1): 010 - 028 


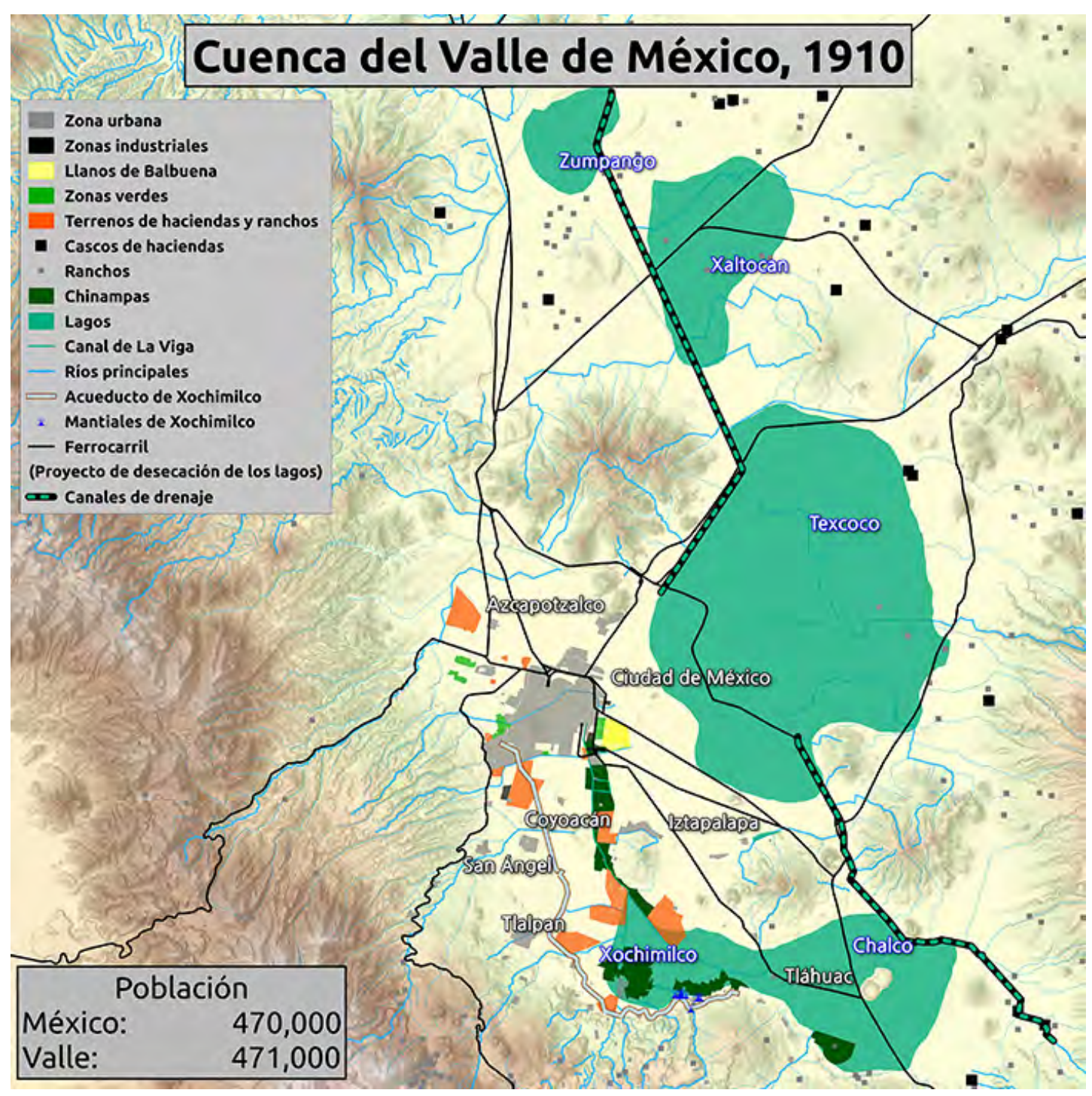

Mapa 1. Cuenca del Valle de México, 1910. Autor: Adrián Flores. Fecha de elaboración: septiembre, 2018.

Fuentes: la cartografía fue elaborada a partir de la digitalización manual de diversos mapas, planos y fotografías de la mapoteca del Archivo Histórico del Distrito Federal.

tabaco, industria textil, cemento, hierro y acero) (Garza, 1985), la exclusión económica, política y social de la mayor parte de la población derivó en la confluencia de una revolución política impulsada por pequeños propietarios rurales (los rancheros) y una revolución social impulsada por campesinos e indígenas despojados (Flores, 2007). El período armado de la Revolución Mexicana (1910-1917) culmina cuando la burguesía rural (el grupo Sonora) asume el control político del país, los campesinos obtienen formalmente el derecho a la dotación de tierras ejidales y las comunidades indígenas la restitución de tierras comunales.

Los ejidos y comunidades fueron las dos formas de propiedad social de la tierra, asentadas en la Constitución de 1917, que permitieron fragmentar las grandes propiedades porfiristas, apaciguar los anhelos agraristas más radicales y fortalecer el poder del Estado moderno. El reparto agrario culminó con la conversión de la mitad del territorio nacional (102,876 millones de hectáreas) (INEGI, 1994) en propiedad social; sin embargo, todos los gobiernos posrevolucionarios utilizaron el reparto de la tierra como una estrategia para cooptar la fuerzas campesinas y emprender proyectos de industrialización y urbanización a nivel nacional (Flores, 2007)9.

9 La presidencia de Gustavo Díaz Ordáz (1964-1970), recordada por la matanza de estudiantes de 1968, repartió 343,5 mil hectáreas mensuales durante su periodo, equivalente al 12\% del país; cifra superior a las 260,9 mil hectáreas repartidas por Lázaro Cárdenas (1934-1949), recordado por la nacionalización de la industria petrolera (INEGI, 1994) 


\section{El reparto ejidal en los alrededores de la Ciudad de México: 1915-1940}

En 1910, en los alrededores de la Ciudad de México, los ejidos y comunidades se extendieron sobre las 11 haciendas y 42 ranchos que existían en el Distrito Federal (Secretaría de Economía, 1956). Entre1915 y 1940, el reparto de30,4 mil hectáreas de tierras ejidales en el Distrito Federal, que además de Ciudad de México incluía pueblos como Azcapotzalco, Tlalpan, Coyocán, Xochimilco e Iztapalapa, impulsó el crecimiento de su población, que pasó de 720 mil habitantes en 1910 a 1,7 millones en 1940 (INEGI, 2015). Si la expansión del sistema ferroviario y eléctrico, consolidados durante el porfiriato, fue una condición necesaria para la concentración industrial y la urbanización de la Ciudad de México (Garza, 1985), los movimientos agrarios constituyeron el fundamento del poder de los gobiernos nacionalistas y populistas para conducir estos dos procesos. Al mismo tiempo, el crecimiento de la población rural y las actividades agrícolas favorecidas por el reparto agrario, permitieron que la expansión de la población obrera urbana accediera a alimentos abundantes y baratos. En este sentido, la cartografía del tsunami inmobiliario resalta el reparto de tierras ejidales durante este periodo para enfatizar sobre la importancia de los movimientos agrarios de la década de los 30's en las organizaciones urbano populares de los siguientes periodos (Ver Mapa 2). De igual forma resalta la interconexión urbana mediante los tranvías eléctricos y la conexión de la ciudad a un suministro constante de hidrocarburos.

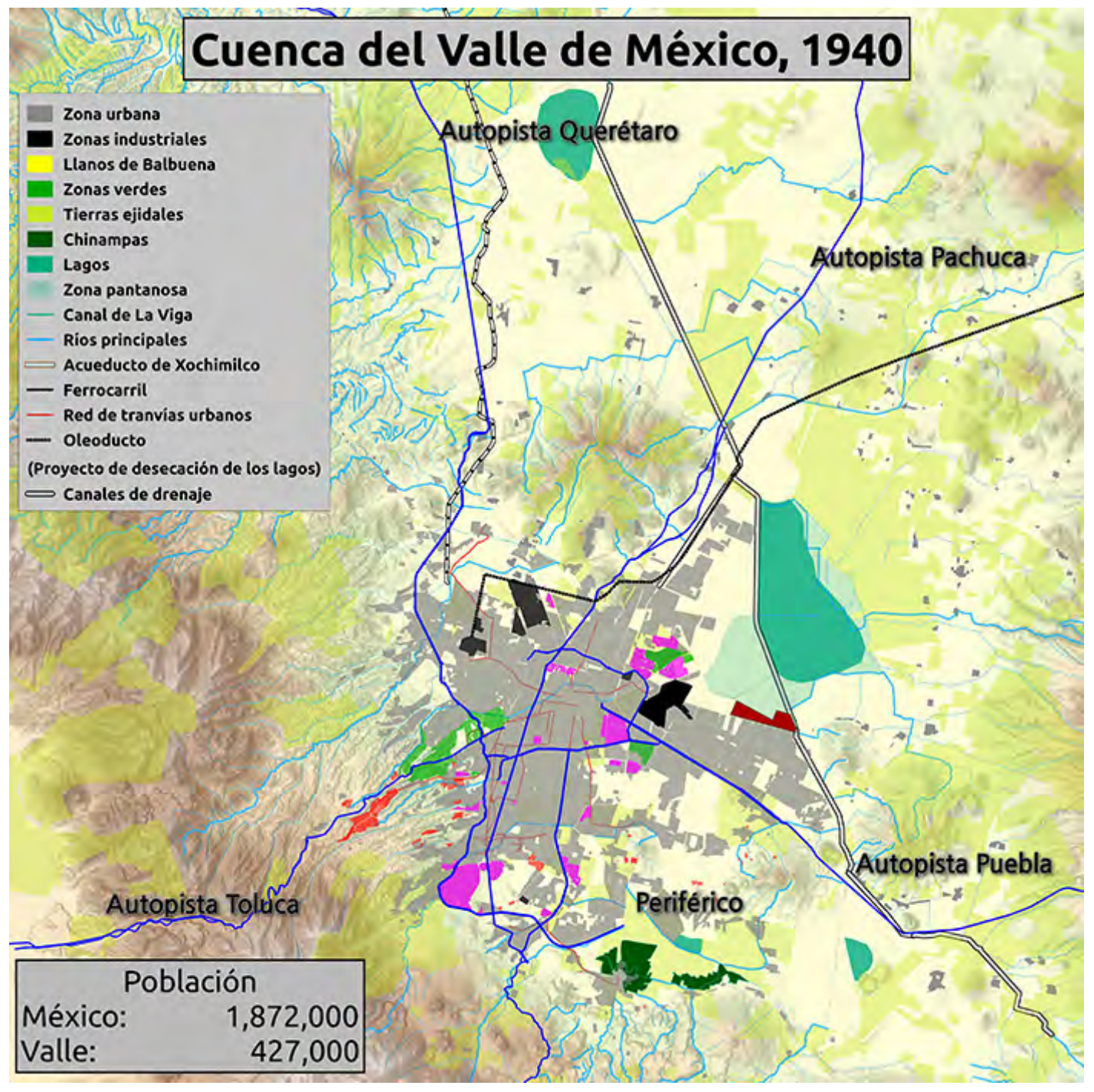

Mapa 2. Cuenca del Valle de México, 1940. Autor: Adrián Flores. Fecha de elaboración: septiembre, 2018 Fuentes: la cartografía fue elaborada a partir de la ubicación manual de los principales proyectos de infraestructura, la incorporación de las primeras tierras ejidales repartidas en el valle de México (sin determinar con precisión los límites) y la digitalización manual de diversos mapas, planos y fotografías de la mapoteca del Archivo Histórico del Distrito Federal. 
La zona chinampera en los bordes de la región lacustre de Xochimilco, Tláhuac y Chalco y la red de canales que los comunicaban con la Ciudad de México, constituyen parte de la infraestructura prehispánica que mantuvo el abastecimiento agrícola urbano hasta la primera mitad del siglo XX (Peralta, 2009) ${ }^{10}$. No obstante, las tierras agrícolas abiertas en los valles de Iztapalapa y la zona montañosa de Tlalpan también aportaban alimentos, los que eran transportados por el Canal de La Viga para su comercio en el mercado de La Merced, construido en 1923, donde también se concentraban los productos de las tierras agrícolas de Texcoco. Pero mientras que las tierras de Iztapala y Xochimilco continuaron con la tradición agrícola, la ubicación de los ejidos de Azcapotzalco, en la confluencia de todas las líneas ferroviarias que llegan a la ciudad, los obligó a competir y a convivir desde el principio con el naciente proceso industrial ${ }^{11}$. Todos estos elementos, ayudan a comprender el carácter de los movimientos y organizaciones urbanas en los siguientes periodos; el carácter agrícola del sur de la ciudad, contrasta con el carácter industrial del norte, y todo ello influye en las distintas formas de enfrentar al tsunami inmobiliario.

Una vez que fueron repartidas las primeras tierras ejidales en la década de 1920, las industrias iniciaron su expansión en el norte de la ciudad. Así, en el rancho de "El Rosario", se instaló la "Fundidora de Hierro y Acero". En 1929, se planeó la expansión de la Zona Industrial Vallejo sobre 50 hectáreas de tierras agrícolas de la hacienda de los Ahuahuetes $^{12}$, y alrededor de los ejidos de Tilhuaca y Ahuizotla, la compañía inglesa "Mexican Eagle Petroleum Company" construyó la refinería en 1933. Azcapotzalco quedó conectado por un oleoducto con los campos petroleros de Veracruz, y después de la expropiación de la industria petrolera, emprendida en 1938 por Lázaro Cárdenas, con el apoyo popular, se convirtió en el núcleo de la industrialización y urbanización del centro del país (Villanueva, 1990; Hernández, 2016) ${ }^{13}$.

Finalmente, aunque en las tierras del oriente de la ciudad también confluían varias líneas de ferrocarril, las actividades agrícolas continuaron siendo predominantes; no obstante, en los terrenos más próximos a la ciudad, se instalaron algunas industrias, como la empresa "Productos Químicos" (AHDF, No. 81) ${ }^{14}$, o algunos basureros, como el Tiradero de Zoquipa, muy próximo a las chinampas de la Magdalena (AHDF, No. $80)^{15}$. Al oriente, también, sobre los llanos de Balbuena, se encontraban las pistas aéreas donde se realizaron las primeras pruebas de vuelo en la ciudad (AHDF, No. $81)^{16}$, las que finalmente fueron trasladadas a los linderos del ejido del Peñón de Los Baños, dotado en 505 hectáreas, en 1927, donde se inauguró el Puerto Central Aéreo, en 1939 (AICM, 2015). La expansión de las pistas se realizó sobre estas tierras ejidales entre 1948 y 1962 (DOF, 27/06/1980; Jimenez, Davil y Trejo, 2012).

10 Las góndolas del tren México-Xochimilco, eran la ruta de transporte alterna para los productos de Xochimilco, sobre todo en los meses de sequía "cuando el nivel de agua bajaba tanto que las canoas tenían que llevar poca carga, para no quedarse atoradas en el lodo" (Peralta, 2009: 462). Pero también constituía un paseo, un punto de encuentro y festejo.

11 El Ejido de Santa Catarina ejemplifica este proceso. En 1929, pobladores de San Marcos, San Martín Xochinahuac y San Andrés, solicitaron la dotación de tierras a la Hacienda de Los Ahuehuetes; en 1934 solicitaron una ampliación, que les fue concedida en 1937. Pero en 1945, les fueron expropiadas 50 hectáreas para la zona industrial de Azcapotzalco y, en 1951, les fue expropiado el resto de sus tierras ejidales (Villanueva, 1990: 43).

12 Esta zona fue decretada en 1944 como parte de la Zona Industrial de Vallejo.

13 Villanueva se basa en el texto de Arteta Begoña y Leticia Algaba (1982) Efemérides de Azcapotzalco, publicado en "Azcapotzalco. Una historia y sus conflictos". Revista de Ciencias Sociales y Humanidades Vol. III, núm. 6-7, mayo-diciembre, UAM-Azcapotzalco. Por su parte, Hernández retoma un post de 2009, firmado por como "Yuri", titulado Zona Industrial de Vallejo, Bosquejo Histórico http://atzcapotzalco.blogspot.com.es/2009/08/zona-industrial-de-vallejo-bosquejo.html 14 Aunque la referencia que ofrece la Planoteca del Archivo Histórico del Distrito Federal no ofrece año de referencia, en la Nota se puede leer la fecha "Abril de 1930".

15 El plano muestra el Tiradero Zoquipa en terrenos que posteriormente se convirtieron en el Parque Balbuena, que aparece en planos a partir de 1923.

16 En este plano aparece el "Campo de Aviación Militar" inaugurado en 1915 sobre los terrenos donde Mario Pani diseñó en 1952 la colonia Jardín Balbuena 


\section{La expansión industrial y el tercer ciclo de urbanización: 1940-1970}

Entre 1940 y 1970, la industrialización de la Ciudad de México fomentó la migración del campo a la ciudad, lo que incrementó la población del Distrito Federal hasta alcanzar los 6.8 millones de habitantes (INEGI, 2015) ${ }^{17}$. La mayor parte de los pueblos y barrios del Distrito Federal fueron absorbidos por la expansión de la Ciudad de México, y algunos pueblos del Estado de México que iniciaron sus propios procesos de industrialización, como Naucalpan, Tlalnepantla y Ecatepec, también se convirtieron en poblaciones conurbadas (Bassols y Espinoza, 2011). De igual forma, el proceso de proletarización de la población rural favoreció que la mayor parte de las tierras agrícolas del Distrito Federal fueran abandonadas y se convirtieran paulatinamente en pastizales; mientras que el uso industrial del agua de los manantiales cercanos a la ciudad, aceleró la desecación del Canal de la Viga, en la década de 1940, y su pavimentación, en 1957 (Peralta, 2009). Aun así, las actividades agrícolas en Xochimilco, Tláhuac e Iztapalapa, lograron trascender esta fase de industrialización y urbanización hasta 1970.

$\mathrm{Al}$ inicio de este periodo, las líneas de ferrocarril que ingresan por el norte a la Ciudad de México, sirvieron como ejes de articulación de dos corredores industriales. En Tlalnepantla, se fundó la fábrica Herramientas México en 1941, y más tarde, la Industria Eléctrica de México (IEM) (Padilla, 1982) que, junto con otras fábricas de cemento, hules y papeleras, dieron origen al principal corredor manufacturero del país. En Ecatepec, la creación de Sosa Texcoco en 1943, a partir de un enorme evaporador solar con forma de caracol, para aprovechar los suelos salinos del Lago de Texcoco en la producción de carbonato y sales de sodio, inició la industrialización de este segundo corredor. Aquí, empresas como Aceros Ecatepec y Compañía Industrial San Cristóbal, instaladas en 1951, al igual que empresas como Quimica Hoescht (1957) y Basf (1964), aprovecharon la política estatal de industrialización, basada en la construcción de infraestructura de transporte, parques industriales, control salarial y exención de impuestos (Bassols y Espinoza, 2011).

La concentración industrial en Azcapotzalco, Tlalnepantla y Ecatepec, reflejada en el crecimiento de los trabajadores industriales en la Ciudad de México, que pasaron de 90 mil en 1940 a 400 mil en 1960 (Garza, 1985), estuvo impulsada por el proceso de ampliación y construcción de nueva infraestructura vial. En 1947, la Avenida Insurgentes se amplió hasta la salida a Pachuca y fue pavimentada en su totalidad para conectar la ciudad, de norte a sur, hasta la salida a Cuernavaca (Casasola, 1992). En 1952, se entubó el Río de la Piedad, que atravesaba la ciudad de Este a Oeste, para convertirlo en la primera vía rápida urbana, el Viaducto; y en ese mismo año, se inauguró la autopista a Cuernavaca. En 1958, se inauguró la autopista que conectaba la Ciudad de México con Querétaro, y entre 1962 y 1964 se concluyeron las autopistas que la conectaban con Pachuca y Puebla. Además, se construyeron los primeros tramos del Circuito Interior y el Anillo Periférico. Todas estas avenidas fueron las vías que facilitaron el primer proceso de expansión urbana, todavía contenido por el anillo periférico.

El único poblamiento masivo realizado en el borde exterior del periférico fue Ciudad Nezahualcóyotl, uno de los ejemplos paradigmáticos de la expansión urbana impulsada por la industrialización durante este periodo. En 1953, fueron vendidos los primeros lotes a migrantes oaxaqueños y poblanos, que buscaban trabajo en las zonas industriales de la Ciudad de México, y accedieron a asentarse sobre los pantanos remanentes del Lago de Texcoco. Para 1960, "Neza" era una ciudad con más de 100 mil habitantes, sin pavimentación, luz, agua ni drenaje. Hasta 1970, la presión ejercida por las organizaciones de $\operatorname{colonos}^{18}$, que sumaban ya 600 mil habitantes, fomentó la

17 Los estudios antropológicos sobre la formación de la clase obrera en Azcapotzalco, concluyen que, antes de ser absorbidos por la industria, los migrantes de origen campesino se incorporan al sector de la construcción y los servicios (Villanueva). 18 Como el Movimiento Restaurador de Colonos (MRC), el Frente Popular Independiente de Nezahualcóyotl (FPIN) y la Unión Independiente de Colonias de Nezahualcóyotl (UNICON).

014 | Espiral 1(1): 014 - 028 


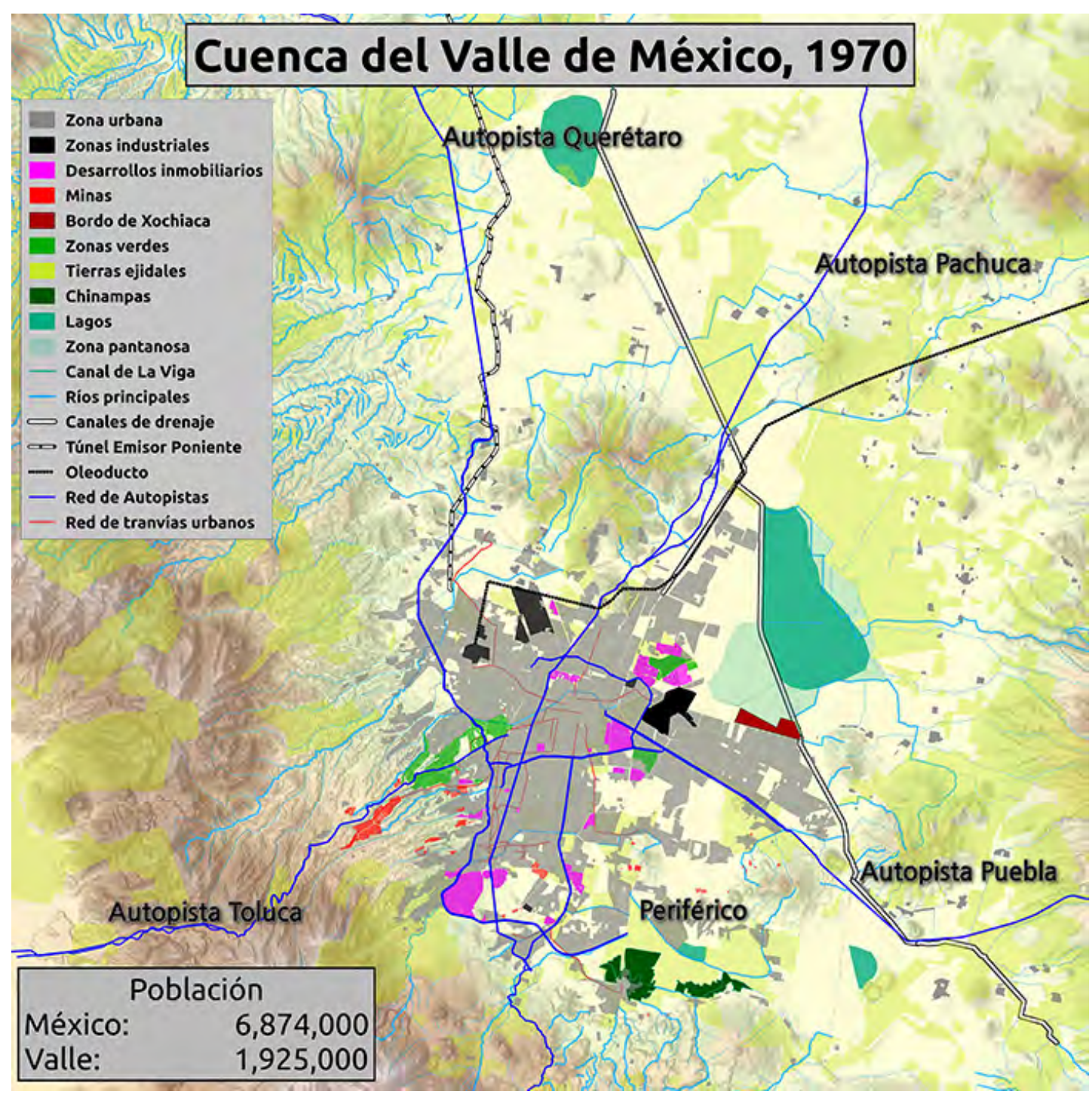

Mapa 3. Cuenca del Valle de México, 1970. Autor: Adrián Flores. Fecha de elaboración: septiembre, 2018

Fuentes: la cartografía fue elaborada a partir de la ubicación manual de los principales proyectos inmobiliarios, industriales y de infraestructura con ayuda de las cartas topográficas de INEGI de 1970.

dotación de servicios y la regularización de los predios por parte del Estado, a cambio del cobro de impuestos y la transformación de su población en un bastión electoral.

En las zonas centrales de la ciudad, algunas empresas inmobiliarias privadas dedicadas a fraccionar o lotificar las tierras para su venta, pero sobre todo instituciones públicas de fomento a la vivienda, en alianza con los sindicatos de trabajadores del estado ${ }^{19}$, fomentaron la creación de las primeras unidades habitacionales. La primera de ellas fue el Conjunto Urbano Presidente Alemán, proyectado por el arquitecto Mario Pani en 1948, en la Colonia del Valle. Un proyecto de Pani totalmente distinto es Ciudad Satélite, creada en 1952, a 17 km de la Ciudad de México, en el municipio de Naucalpan; aunque originalmente se trataba de un proyecto de vivienda para la clase trabajadora, el "fraccionamiento" -como comúnmente se conoce a los desarrollos inmobiliarios privados- fue habitado por profesionistas, burócratas y empresarios con automóvil. Otro proyecto de vivienda obrera de Pani es el Conjunto Urbano Presidente Adolfo López Mateos, en Tlatelolco, donde en 1962 se construyeron 12 mil viviendas que permitieron desplazar, del centro de la ciudad, a más de 7 mil personas que habitaban a lo largo de las líneas del ferrocarril, en lo que Pani llamaba la herradura de tugurios. 
Finalmente, el desplazamiento de la Ciudad Universitaria de la Universidad Nacional Autónoma de México, desde el centro de la ciudad hacia el pedregal de San Ángel, en 1952, constituye otro de los proyectos que definió la expansión urbana durante este periodo. Al poniente, fomentó el poblamiento del proyecto urbano de Jardínes del Pedregal, diseñado por un selecto grupo de arquitectos, en colaboración con artistas plásticos de la época, para las familias más poderosas del país. Al oriente, en cambio, sobre la misma lava volcánica del Xitle, alrededor de 5 mil familias migrantes de Puebla, Oaxaca y de otros pueblos de la ciudad, emprendieron la urbanización del Pedregal de Santo Domingo. A diferencia de la urbanización dirigida por el Estado o por las empresas, la urbanización popular contaba únicamente con el trabajo y la organización de sus propios habitantes para emparejar el terreno, para introducir servicios básicos como luz, agua y drenaje y para emprender proyectos educativos y de salud. Aun así, debido al control del Estado sobre los fraccionamientos o lotificaciones privadas, fue principalmente la urbanización popular la que se extendió sobre el valle de México, y es ésta la que actualmente otorga el carácter distintivo a la Ciudad de México.

Al final de este periodo, la Ciudad de México concentraba el $42 \%$ de los obreros del país y el $48 \%$ del valor agregado de toda la producción industrial. Las condiciones generales para la producción habían sido prácticamente establecidas a partir del financiamiento público. La ciudad contaba con una red de transporte que facilitaba la circulación de mercancías, se encontraba conectada a los principales centros de extracción y transformación de hidrocarburos, gracias a un sistema de oleoductos y gasoductos. Asimismo, contaba con una red de energía eléctrica y sistemas de abastecimiento de agua potable. Sin embargo, gran parte de las condiciones para la reproducción de los trabajadores debieron ser puestas por estos últimos. De acuerdo con diversos cálculos (Garza y Schteingart, 1984; Schteingart, 1987), entre 1950 y 1970, la superficie ocupada por colonias populares creció del 23 al 40\%, mientras que su población aumentó de 14 a 40\%; pese a lo sorprendente del dato, las cifras deben ser corroboradas por nuevas técnicas cartográficas para tener un dato preciso de la expansión urbana durante este periodo. Lo cierto es que el crecimiento de los nuevos barrios obreros compitió con los antiguos barrios y ejidos campesinos, que rodearon la ciudad de México en el periodo anterior y que, gracias a la producción de alimentos, constituyeron el fundamento para la expansión de la población obrera. Durante todo el siguiente ciclo, la explosión urbana de carácter obrero se extendió sobre terrenos agrícolas que fueron abandonados paulatinamente.

\section{Desindustrialización y el cuarto ciclo expansivo: 1970-2000}

Hacia 1974, la expansión industrial comandada por el Estado entró en un proceso de recesión generalizada que, para 1982, se convirtió en una profunda crisis del modelo de sustitución de importaciones impulsado por los gobiernos populistasnacionalistas. Esta crisis derivaba, en gran medida, de la reestructuración del sistema capitalista global hacia el neoliberalismo y la gestión del desplome de la hegemonía estadounidense. Sin embargo, precisamente en este periodo, el Estado mexicano encontró las mayores reservas de petróleo de su historia y aumentó su producción de 200 mil hasta 1 millón de barriles diarios de crudo, lo que le permitió contar con una extraordinaria fuente de recursos para mantener los procesos de industrialización y urbanización durante una década. Aunque el crecimiento industrial se mantuvo hasta 1980, en este periodo el Estado se dedicó a completar la infraestructura de servicios urbanos, particularmente la infraestructura vial. Pero a partir de 1982, el gobierno abandonó esta función y se limitó a transferir la mayor parte de la industria nacional a capitales privados; fue en este contexto que estalló la crisis urbana, expresada nítidamente después del primer sismo del 19 de septiembre de 1985.

La población del Distrito Federal alcanzó su máximo crecimiento en 1980, con 8.8 millones de habitantes, y comenzó a descender ligeramente hasta alcanzar 8.6 millones en el año

016 | Espiral 1(1): 016 - 028 


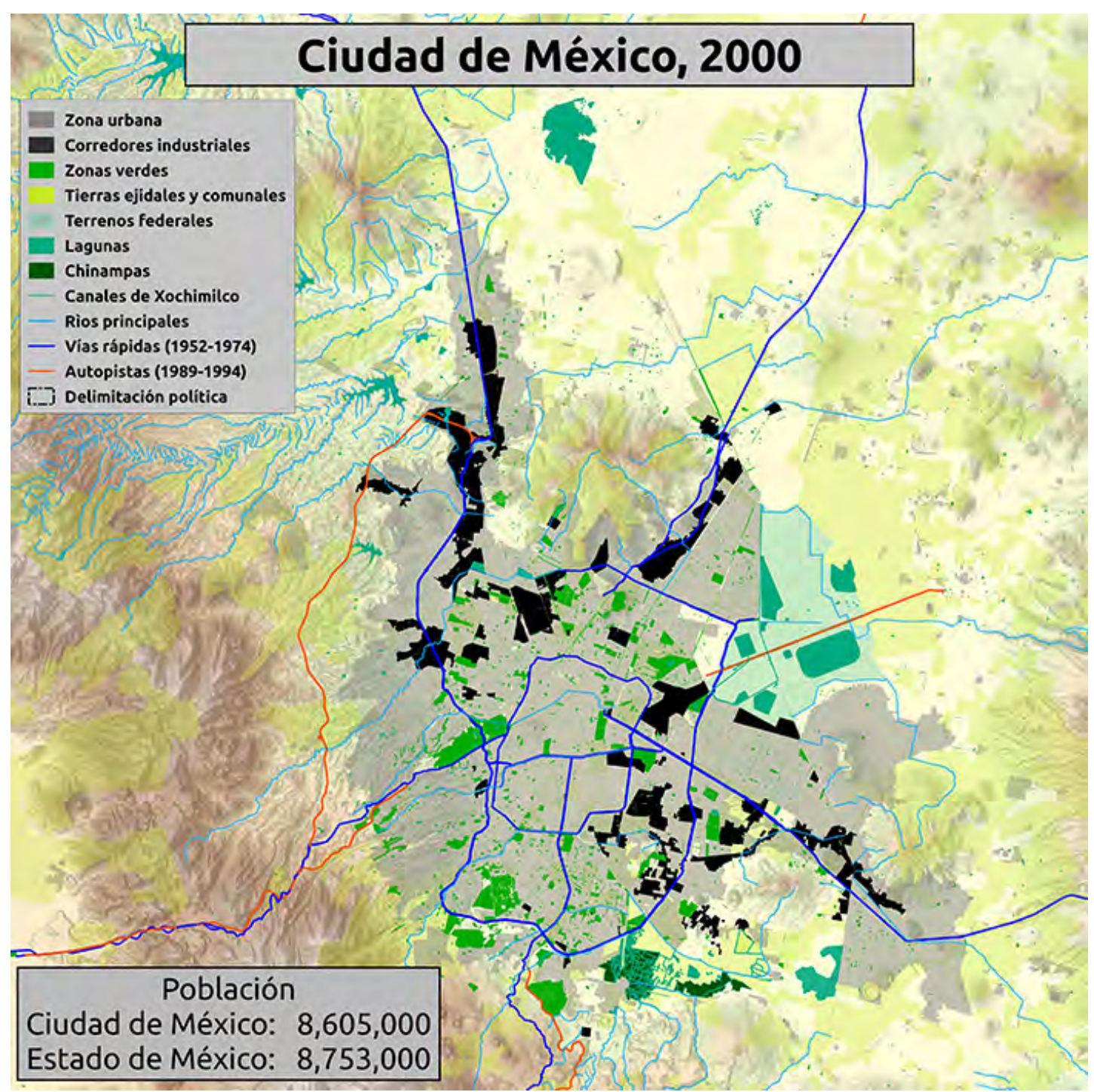

Mapa 4. Ciudad de México, 2000. Autor: Adrián Flores. Fecha de elaboración: septiembre, 2018.

Fuentes: la cartografía fue elaborada a partir de la ubicación manual de los principales proyectos industriales y de infraestructura de transporte con base en la cartografía urbana de INEGI

2000. En cambio, la población de los municipios conurbados creció de 1.9 millones en 1970 hasta 8.7 millones en 2000, principalmente a partir de población migrante del Distrito Federal, pero también de otros Estados del país (ver Mapa 4). En el contexto de crisis económica, el acelerado crecimiento de la población provocó el aumento del desempleo, que en 1974 alcanzaba la cifra de 220 mil personas, y en el contexto del neoliberalismo, también se expresó en la precarización de los empleos formales. Para la década de 1980, la invasión de tierras ejidales y la venta ilegal de terrenos se convirtieron en las principales formas de urbanización en la Ciudad de México.

Bajo este esquema se creó la mayor parte de las colonias en Iztapalapa, Coyoacán, Tlalpan y Álvaro Obregón en el Distrito Federal, y en los municipios de Chalco, Ixtapaluca, Chimalhuacán, Ecatepec, Tecámac, Coacalco, Tutltitlán, Cuautitlán, Atizapán, Tlalnepantla, Naucalpan y Huixquilucan. De 1980 a 2000, la superficie de la Ciudad de México aumentó de 60 a 115 mil hectáreas, con la incorporación de 26 municipios del Estado de México. Esta nueva metrópoli mantenía a casi 65\% de sus habitantes en condiciones de marginalidad, con viviendas irregulares, servicios precarios, empleos inestables y salarios bajos. Mientras que las clases medias y altas, que representaban alrededor del $35 \%$ de sus habitantes, residían en fraccionamientos diseñados por empresas inmobiliarias subsidiadas o comandadas por el Estado ${ }^{20}$.

20 De acuerdo con Martha Steinghardt, “entre 1960 y 1977 fueron aprobados, en diferentes municipios del Estado de México, unos 150 fraccionamientos que cubren aproximadamente el 36\% del crecimiento de la mancha urbana en ese estado". 
En su intento por frenar la urbanización popular, a la que se le denominó "urbanización descontrolada", el Estado favoreció los fraccionamientos privados de múltiples formas. En primer lugar, transfirió su competencia de promoción y financiamiento de vivienda a constructoras y financiadoras privadas. En segundo lugar, reformó las leyes agrarias para promover que ejidatarios y comuneros negociaran sus terrenos de manera individual, de forma que las empresas privadas pudieran comercializar legalmente el suelo ejidal y comunal. En tercer lugar, los fraccionadores privados aprovecharon la política de construcción de ejes viales durante el gobierno de Carlos Hank González (1976-1982), para 'acercar' al núcleo urbano los terrenos periféricos que compraban a bajos precios, todavía de manera irregular, pues la compra-venta de tierras ejidales estuvo prohibida por la legislación agraria hasta 1992.

Al mismo tiempo, la densificación de redes viales en el interior de la ciudad aceleró el proceso de reducción de espacios públicos, la agudización de los desalojos violentos, las expropiaciones y el incremento de las rentas. Se puede decir que los ejes viales contribuyeron a articular y masificar a los movimientos urbanos en la Ciudad de México que, para 1984, estaban constituidos en una coordinadora regional que aglutinaba más de 40 barrios obreros en torno a una compleja variedad de problemáticas urbanas ${ }^{21}$. La coordinadora era capaz de movilizar hasta 60 mil colonos en marchas y concentraciones en la capital.

Cuando ocurrió el sismo de 1985, el movimiento urbano popular tenía claro el papel que el gobierno desempeñaba en la promoción del suelo urbano como una mercancía y aprovechó el abandono de la cuestión urbana por parte del gobierno para recuperar su presencia en el núcleo urbano, donde se registró la mayor cantidad de edificios colapsados. Esta coyuntura expulsó a muchas familias de clase alta desde las zonas de mayor riesgo del núcleo urbano (con suelos lacustres) hacia las periferias más rocosas del poniente. Ahí fue donde el gobierno de la ciudad ensayó la primera forma de atracción del capital financiero hacia el suelo urbano. En 1987, una mina de arena de $4 \mathrm{~km}$ de largo y 100 metros de profundidad, perforada por la industria de la construcción en la década de 1940 y que en 1957 se convirtió en el principal relleno sanitario de la ciudad, fue comprada por una empresa del gobierno (Servimet) con el objetivo de generar un polo de atracción de viviendas y oficinas para el sector urbano de altos ingresos.

Para financiar este desarrollo, el Departamento del Distrito Federal (DDF) diseñó las Zonas Especiales de Desarrollo Controlado (ZEDEC), incorporadas en el Programa General de Desarrollo Urbano del Distrito Federal (PGDU), en donde el gobierno podría concentrar la inversión pública para la dotación de servicios urbanos. En el caso de la ZEDEC Santa Fe, este mecanismo facilitó transferir la plusvalía generada con fondos públicos, hacia los capitales interesados en la inversión inmobiliaria. Para conectar este desarrollo con el núcleo urbano, en 1989, el gobierno federal otorgó una de las primeras concesiones privadas para la construcción de la autopista MéxicoToluca. Y para animar aún más a los inversionistas privados, en 1992 modificó la ley agraria y la ley de vivienda, para facilitar la compra de tierras ejidales y fomentar a la industria inmobiliaria, respectivamente. Finalmente, en 1994, el gobierno federal firmó el Tratado de Libre Comercio de América del Norte (TLCAN), a partir del cual el capital trasnacional por fin aceptó instalarse en Santa Fe y convertir este antiguo basurero en el polo financiero de la Ciudad de México.

En este tránsito, el Distrito Federal redujo su participación industrial hasta el $18 \%{ }^{22} \mathrm{e}$ inició el proceso de tercerización económica, es decir, la concentración del empleo en el

21 Desalojos, reubicaciones, regularización de la lotificación, remodelación urbana, rentas excesivas, regeneración de viviendas, autoadministración en edificios, acceso al agua, reconocimiento de la urbanización popular, solicitud de tierra, transporte, aumento de impuestos, salario, educación, contaminación ambiental y la democratización de la ciudad en general 22 En 1970, la Ciudad de México, en su conjunto, aportaba el 56\% del PIB manufacturero del país (el Distrito Federal aportaba el 32\% y el Estado de México el 17\%). Para el año 2000, la manufactura en el Distrito Federal disminuyó al 18\% y en el Estado de México apenas al 16\%, lo que significó una reducción conjunta de hasta el 45\%.

018 | Espiral 1(1): 018 - 028 
sector financiero y el refugio de 6 millones de trabajadores en la economía informal de la Ciudad de México ${ }^{23}$. La tercerización fue responsable de; la pérdida del $78 \%$ del poder adquisitivo del salario de sus los trabajadores ${ }^{24}$, la construcción de 145 centros comerciales ${ }^{25}$, la expansión de 7 millones de automóviles ${ }^{26}$ y, en resumidas cuentas, en fin, el inicio de la urbanización salvaje: el libre tránsito del capital desde el sector financiero hacia el suelo urbano. El único dique a este proceso, son los restos del movimiento urbano popular que, entre 1940 y 1980, logró la alianza del sector campesino y obrero. También entre esos años, adquirió experiencia en la defensa de sus intereses frente al Estado populista y a los capitales industriales nacionales, y mantuvo presencia tanto en el núcleo urbano como en sus periferias. El gran problema es que; pero que carece de experiencia frente a la alianza entre el Estado neoliberal y el sector financiero trasnacional.

\section{La urbanización salvaje y la batalla por el suelo urbano: 2000-2018}

Desde 1997, tan pronto como los habitantes del Distrito Federal tuvieron la posibilidad de elegir por la vía electoral al Jefe de Gobierno ${ }^{27}$, buscaron alejarse de las prácticas políticas del partido de Estado hegemónico. A partir del año 2000, las diferencias entre las formas políticas del Distrito Federal y los municipios conurbados de la Ciudad de México, pertenecientes al Estado de México, tomaron dos rutas de urbanización distintas. En el Distrito Federal se dictó un decreto conocido como Bando Dos, que buscaba restringir el crecimiento de "unidades habitacionales y desarrollos comerciales que demanden un gran consumo de agua e infraestructura urbana" en las delegaciones periféricas (urbanizadas entre 1970 y 2000). Al mismo tiempo, el bando dos buscaba promover el repoblamiento de las cuatro delegaciones centrales (Benito Juárez, Cuauhtémoc, Miguel Hidalgo y Venustiano Carranza) ${ }^{28}$ a partir de la "construcción de vivienda para la gente humilde de la ciudad". Bajo esta política de redensificación con vivienda popular, se privilegió el asentamiento de más de 130 mil familias de bajos ingresos en el núcleo urbano de la ciudad. El mapa 5 , muestra los resultados territoriales de esta polémica y ambigua política urbana, que inició como un proceso de densificación del núcleo urbano para familias de escasos recursos controlado por el gobierno local y terminó como el primero de múltiples pasos que facilitaron paulatinamente la apropiación del suelo urbano por el capital financiero.

\subsection{El triunfo de los ejidatarios contra el aeropuerto: "La tierra no se vende, se ama y se defiende"}

En este mismo periodo, en el Estado de México, el gobierno federal planteó la construcción de un nuevo aeropuerto que impulsaría una economía regional a partir de la expropiación de las tierras ejidales de Atenco, Texcoco y Chimalhuacán. El proyecto, que formaba parte del Plan Puebla Panamá, motivó la creación del Frente de Pueblos en Defensa de la Tierra (FPDT), al que se ofreció el pago de $\$ 7$ por metro cuadrado de tierras agrícolas de temporal y $\$ 25$ por metro cuadrado de

23 Para 2012, la economía informal absorbe al 48,9 \% de la población ocupada en el Distrito Federal, y 58,7 \% del Estado de México" (Pradilla, 2016).

24 En 1987, el salario mínimo mensual era de \$6.47 y la canasta básica tenía un costo de \$3.95; mientras que, en 2015, aunque el salario mínimo al mes asciende a $\$ 70.10$, la canasta básica cuesta $\$ 201$, de modo que, si antes un trabajador debia trabajar 4 horas para obtenerla, actualmente debe emplearse durante 23 horas para lograr adquirirla (CAM; 2015) 25 Entre 1960 y 1980 se construyeron 17 centros comerciales en la ciudad. Para el año 2000, existían 162; en 2012 había ya 262 (Pradilla, 2016) y en 2018 pueden llegar a 500. Otros datos indican que “En 1969 el Distrito Federal tenía un centro comercial; en 1980 se sumó el segundo; en 1990 ya había nueve; al concluir esa década, en el 2000, sumaban 49; en el sexenio 2000-2006, fueron construidas siete plazas comerciales; en 2007-2012, 16 más, y entre 2013 y 2017, en tan solo cuatro años, se han construido 33" (Batres, 2017).

26 La Ciudad de México contaba con 2 millones de automóviles, en 1980; con 3.3 millones, en 2000, y con 8.8 millones, en 2014 (Pradilla, 2016). Incluir gráfica INEGI.

27 Desde 1929 a 1997, el Distrito Federal era administrado por un regente designado directamente por el presidente de la República.

28 Entre 1970 y 2000, estas cuatro delegaciones perdieron 1.21 millones de habitantes, pasando de 2.9 millones en 1970 a 1.6 en 2000. Benito Juárez: 360 mil; Cuauhtémoc: 521 mil; Miguel Hidalgo: 352 mil; Venustiano Carranza: 462 mil.

Espiral 1(1): 019 - 028 | 019 
tierras agrícolas de riego, a cambio de 5,391 hectáreas. Desde el principio, la oferta fue rechazada por los ejidatarios, organizados tras una consigna que dicta la filosofía de resistencia: "la tierra no se vende, se ama y se defiende". Finalmente, el megaproyecto fue cancelado en agosto de 2001.

El "triunfo" parcial de los ejidatarios de Atenco, durante los primeros dos años del ciclo del tsunami inmobiliario este primer ciclo, parecía indicar que la organización popular tenía la fuerza para incidir en las políticas públicas del Distrito Federal e incluso del gobierno federal. No obstante, en este ciclo toma forma la conformación del megaproyecto urbano, la megalópolis de la Ciudad de México, construida a partir del avance molecular de proyectos, aparentemente desconectados entre sí, pero integrados en una lógica territorial que se expresa, también de forma fragmentaria, en los planes sectoriales y políticas públicas metropolitanas. Al poner todas las piezas juntas, la cartografía del tsunami inmobiliario permite comprender la lógica territorial que debieron asumir los capitales en su proceso de apropiación del suelo urbano.

\subsection{La alianza del sector inmobiliario con los presidentes municipales en el}

\section{Estado de México}

Ante la regulación estatal de las construcciones masivas en el Distrito Federal y la imposibilidad del gobierno federal para impulsar proyectos regionales, los municipios conurbados del Estado de México emprendieron un intenso proceso de urbanización, basado en una alianza entre el sector inmobiliario y la estructura política municipal. Bajo este esquema, en sólo diez años, se construyeron más de 550 mil viviendas de interés social, concentradas principalmente en las tierras agrícolas y ejidos de Ecatepec (65 mil), Tecámac (59 mil), Ixtapaluca (56 mil), Chimalhuacán (46 mil), Nicolás Romero (33 mil), Cuautitlán, Tultitlán y Chalco (con 30 mil cada uno), y Chicoloapan (27 mil) (Ver "desarrollos horizontales" en Mapa 5).

Este primer ciclo de urbanización salvaje en la periferia de la Ciudad de México ${ }^{29}$, benefició principalmente a empresas como SADASI, URBI, Casas GEO, Casas Ara, Homex así como a varias decenas de pequeñas constructoras, muchas de ellas "piratas" ${ }^{30}$, que transformaron miles de hectáreas de terrenos agrícolas en suelos urbanos. Además, trastocaron los sistemas comunitarios de gestión de agua y promovieron la instalación de basureros junto a la nueva vivienda (Tepojaco y Tecámac) con base en la corrupción, y sobre todo, la división y represión (a nivel municipal) ${ }^{31}$ de los pueblos que intentaban oponerse a este proceso.

Conforme los nuevos asentamientos periféricos sumaban más trabajadores a los desplazamientos pendulares hacia el Distrito Federal, los sistemas de transporte urbano tradicionales comenzaron a saturarse. La insuficiencia de la red de carreteras federales, producida por la nueva urbanización, otorgó legitimidad a la construcción de grandes obras viales privadas. En realidad, este primer ciclo de urbanización salvaje, hubiera sido imposible sin el respaldado otorgado por el auge en la construcción de autopistas de acceso controlado, concesionadas a grandes empresas constructoras.

Aunque este proceso inició en 1994 con las autopistas de Toluca y Texcoco, el auge inició a partir de 2005 con la concesión del Circuito Exterior Mexiquense a la empresa española OHL, y del Arco Norte a la empresa constructora IDEAL de Carlos Slim, en 2006, IDEAL. Fuera de los planes originales de infraestructura planteados

29 Si de entre 1970 ya 2000 operó una urbanización descontrolada en el Distrito Federal, emprendida por organizaciones de colonos que ocuparon sus predios sin que el gobierno pudiera regularlos, entre 2000 y 2010, los gobiernos municipales del Estado de México emprendieron el primer ciclo de urbanización salvaje a partir de una alianza con el sector inmobiliario. 30 Es decir, que no se encuentran registradas oficialmente.

31 A partir del control de la prensa local, los presidentes municipales lograron ocultar los movimientos necesarios para avanzar pequeños negocios familiares que afectaban a los pequeños ejidos y pueblos metropolitanos.

020 | Espiral 1(1): 020 - 028 
por el gobierno federal ${ }^{32}$, el diseño de estos dos proyectos permitió enlazar las urbanizaciones periféricas a partir del emplazamiento de dos anillos viales que dan forma a la megalópolis de la Ciudad de México y, debido a la gran cantidad de expropiaciones y conflictos generados por su construcción, constituyeron las dos cartas más importantes del grupo Atlacomulco, para generar la confianza de los capitales que le permitieron recuperar el control del gobierno federal ${ }^{33}$.

\subsection{La Norma 26 y el cártel inmobiliario en la Ciudad de México}

En la pugna por el control del gobierno federal, la administración del Distrito Federal (2007-2012) también jugó sus cartas. Realizó la expropiación de una colonia entera (La Malinche) para favorecer la concesión de la SuperVía Poniente a OHL; integró el segundo piso de periférico a partir de la construcción de la Autopista Urbana Norte y Sur; y en materia de suelo urbano, derogó el bando dos para permitir la construcción de vivienda masiva en todas las delegaciones e invitó al capital privado a colaborar en la construcción de vivienda popular, bajo la regulación de la Norma para impulsar y facilitar la construcción de vivienda de interés social y popular en suelo urbano, conocida como Norma 26.

La aprobación de la Norma 26 se anticipó a la crisis inmobiliaria de 2009, y permitió que el fracaso de la construcción periférica se extendiera sobre el núcleo urbano. En ella, el precio de la vivienda de interés social se fijó en hasta 15 veces el salario mínimo anualizado (vsma) ${ }^{34}$, y en 30 vsma para vivienda popular ${ }^{35}$, el área máxima construida se estableció en $65 \mathrm{~m}^{2}$ el área máxima construida; y se reguló la construcción de niveles de acuerdo a una zonificación que permitía 6 niveles en el Centro Histórico, 5 niveles en el primer entorno (Circuito Interior), 4 niveles en el segundo entorno (Periférico), y sin restricciones ninguna restricción en el tercer entorno (límites del Distrito Federal).

Aunque la Norma 26 originalmente planteó la regulación de la ocupación del capital privado sobre el suelo urbano, en realidad fue este el instrumento que "abrió la puerta" de la Ciudad de México a la entrada masiva de capitales inmobiliarios y consolidó la estrategia del cártel inmobiliario sobre la Ciudad de México. Así como los presidentes municipales del Estado de México sirvieron al sector inmobiliario para emplazarse sobre la periferia urbana, a partir de unidades habitacionales horizontales, los funcionarios del Distrito Federal sirvieron para iniciar la ocupación del núcleo urbano mediante unidades habitacionales verticales.

Entre 2007 y 2013, la Norma 26 impulsó el florecimiento de cientos de empresas que supuestamente comercializaban viviendas de interés social en el centro de la ciudad, en alianza con un puñado de empresas enfocadas en la construcción de vivienda media y residencial, es decir para sectores de ingresos medios y altos. Gracias a sus vínculos con las estructuras políticas delegacionales (nivel municipal), estas empresas lograron evadir las regulaciones de construcción por la vía de amparos, hasta que la Norma 26 fue finalmente suspendida por su incapacidad para impedirlo. Sin embargo, para este momento, el gobierno de la Ciudad de México ya había sido tomado por el cártel inmobiliario.

Una docena de empresas beneficiadas por la norma 26, como Baita, Dekah, Quiero Casa y un conjunto de pequeñas constructoras familiares ${ }^{36}$, posicionaron a Miguel Ángel Mancera $^{37}$ como Jefe de Gobierno del Distrito Federal para el periodo 2012-2018.

32 Controlado por el Partido Acción Nacional (PAN)

33 Desde que asumió el cargo como gobernador del Estado de México (2006-2012), Enrique Peña Nieto (actual presidente de México) se encargó de desmantelar la organización popular mediante el despliegue de la ingeniería del conflicto, la represión del FPDT y el encarcelamiento de su líder, Ignacio del Valle.

34 A precios de 2018 equivale a $\$ 475$ mil pesos (US\$25,000)

35 Equivalente a $\$ 950$ mil pesos (US\$50,000)

36 Existe un registro de más de 600 empresas inmobiliarias que operan en la Zona Metropolitana de la Ciudad de México; un reportaje reciente señala los vínculos de diez familias con empresas como Metra, Eli, BICYQ, Movica, Becerril, SINELA, RADIATAS, Parnelli, Hogares Unión, GIM, Reforma, Neumet, MOIS, MEZ Uno, AM, JAYSI, AGRIMIN.

37 Apoderado legal de BAITA entre 1995 y 2004.

Espiral 1(1): 021 - 028 | 021 
En su administración, otros miembros y representantes legales del sector inmobiliario ocuparon puestos clave del gobierno. Simón Neumann, fundador de Inmobiliaria Dekah en 2003 y director de la Secretaría de Desarrollo Urbano y Vivienda (SEDUVI) entre 2012 y 2014, constituye el personaje clave de este proceso. Sus primeros movimientos fueron la creación y promoción de "CDMX" como la marca comercial de la Ciudad de México, y la creación de la Agencia de Promoción de Inversiones y Desarrollo para la Ciudad de México (ProCDMX) ${ }^{38}$, desde la que impulsó el modelo de ciudad compacta y la política de redensificación del núcleo urbano, a partir de la promoción de inversiones privadas en el sector inmobiliario.

\subsection{Fibras y ZODES: el fracaso del control del capital inmobiliario}

Una vez que cancelaron las Normas 26, la alianza entre el capital inmobiliario y el sector público se articuló en torno de la promoción de los Fideicomisos de Inversión en Bienes Raíces (FIBRA) que iniciaron operaciones en 2011. Las FIBRAs, basadas en los fondos de inversión inmobiliaria conocidos como REIT (Real State Investment Trust) ${ }^{39}$, han favorecido la expansión de edificios de oficinas, centros comerciales, hoteles y parques industriales controlados por portafolios de inversión en manos del capital global, en los que también participan "democráticamente" los capitales locales.

Las Fibras articulan diversos productos fiduciarios que favorecen la asociación de terratenientes con constructores (fideicomisos $\mathrm{A}+\mathrm{B}$ ), la renta de inmuebles ya construidos (fideicomisos de renta), la colocación de deuda en la Bolsa Mexicana de Valores (BMV) para impulsar construcciones nuevas (fideicomisos emisores), y la asociación del gobierno y el capital para construir infraestructura (fideicomisos público-privados). Entre 2011 y 2018, se han creado una docena de FIBRAs que controlan miles de inmuebles en todo el país, aunque la megalópolis de la Ciudad de México es sin duda el principal mercado.

En 2016, Fibra Uno controlaba 7.4 millones de metros cuadrados en 497 propiedades (325 comerciales, 105 industriales y 89 de oficinas $)^{40}$, concentradas particularmente en Ciudad de México (1.2 millones de $\mathrm{m}^{2}$ en 109 propiedades) y en Estado de México (2.8 millones de $\mathrm{m}^{2}$ en 65 propiedades) ${ }^{41}$, donde renta espacios a tiendas de autoservicio, servicios educativos, bancos, servicios de alimentos, entretenimiento, estacionamientos, servicios de hospedaje y logística. Aunque las FIBRAs no han incorporado aún el sector de vivienda, el florecimiento de desarrollos inmobiliarios entre 2014 y 2018 está vinculado con el impulso derivado de las Fibras (Ver "Predios de Fibra Uno" en Mapa 5).

Una vez con el instrumento financiero, se diseñaron las Zonas de Desarrollo Económico y Social (ZODES) como un instrumento de planeación que permitiría concentrar la inversión derivada de las FIBRAs hacia zonas estratégicas que le permitieran al gobierno del Distrito Federal conducir el proyecto de densificación urbana. Los 5 proyectos de ZODES encargados de "recuperar" el suelo urbano a partir de la construcción de infraestructura urbana fueron Ciudad de la Salud, Ciudad Administrativa, Ciudad Futura, Ciudad Verde y el Corredor Cultural-Creativo.

\footnotetext{
38 Dirigida por Simon Levy, encargado de la promoción FIBRAS-ZODES.

39 “Este tipo de vehículo de inversión tiene su origen en Estados Unidos donde se le conoce como REITs (por sus siglas en inglés Real Estate Investment Trusts), y fueron creados para proporcionar al público inversionista un mecanismo de inversión en grandes proyectos inmobiliarios. Su éxito radica en que son entidades que brindan atractivos rendimientos con un bajo nivel de riesgo. Es decir, en el caso específico de las fibras, una o varias personas, fideicomitentes portan (trasmiten la propiedad) de dinero y/o bienes inmuebles a un fideicomiso, el cual emitirá certificados fiduciarios que otorgará a los tenedores (fideicomisarios) ciertos derechos y que, por lo menos, representarán el valor del patrimonio aportado con el fin de que el fideicomiso 'se dedique a la adquisición o construcción de bienes inmuebles que se destine al arrendamiento o a la adquisición del derecho a percibir ingresos provenientes del arrendamiento de dichos bienes, así como a otorgar financiamiento para lograr esos fines'” (Zurita, 2007).

403 millones de $\mathrm{m}^{2}$ comerciales (40\%), 3.6 mill, de $\mathrm{m}^{2}$ industriales (48\%) y 0.8 mill. de $\mathrm{m}^{2}$ de oficinas (11.5\%)

41 Ciudad de México concentra el 16.9\% de la superficie de Fibra Uno, Estado de México 38.9\%, Jalisco, 10.8\%, Nuevo León 7.8\%, Tamaulipas 4.5\% y Quintana Roo 3.6\%.
}

022 | Espiral 1(1): 022 - 028 
Para 2015, el rechazo de los habitantes de Pedregales de Santo Domingo (quienes defendieron el poblamiento popular emprendido en 1971) contra Ciudad del Futuro y el rechazo generalizado expresado en un plebiscito contra el Corredor CulturalCreativo sobre Avenida Chapultepec, se convirtieron en los referentes del fracaso de las ZODES, es decir, del proyecto del gobierno de la ciudad para controlar al capital inmobiliario. Sin embargo, el proyecto de ocupación del suelo por el sector inmobiliario se mantiene en pie.

\subsection{La lucha popular contra el sector inmobiliario}

Actualmente, la figura de Neumann ha quedado desgastada tras su paso por SEDUVI, el fracaso de las ZODES y su asesoría a los Centros de Transferencia Modal (CETRAM), y su destino es similar al de los presidentes municipales que facilitaron la entrada del capital inmobiliario en el Estado de México. No obstante, su proyecto prosperó, la Ciudad de México quedó expuesta a los efectos del tsunami inmobiliario. La expansión de la empresa constructora "Quiero Casa" representa el avance del sector inmobiliario en los últimos años. Entre 2014 y 2018, esta empresa ha construido 55 complejos habitacionales con más de 6 niveles, en los que suma más de 2,826 departamentos de aproximadamente $50 \mathrm{~m}^{2}$, vendidos por más de 2.4 billones (millones de millones) de pesos.

Vecinos y compradores de estos mega-desarrollos denuncian apropiación irregular de tierras ejidales, violaciones de normativas urbanas sobre suelos de conservación, excavaciones sin permiso, violaciones a los estudios técnicos y a las manifestaciones de impacto ambiental. Además, se denuncia la tala clandestina de árboles, dictámenes de impacto urbano apócrifos, daños a las casas y a la infraestructura urbana aledaña, violación de medidas de protección civil, adeudos de luz, incumplimiento en la entrega de la Manifestación de terminación y ocupación de obra, múltiples vicios ocultos en los inmuebles entregados, sobrepoblación, saturación de las redes viales, sobrexplotación de agua. No existe autoridad que pueda sancionar a la empresa.

El caso más paradigmático lo constituye el predio de $8.7 \mathrm{mil} \mathrm{m}^{2}$ de Aztecas 215, en el Pedregal de Santo Domingo, donde las perforaciones de cimentación realizadas para la construcción de 377 departamentos sobre 3 niveles de estacionamientos subterráneos, fueron realizadas sin ningún estudio técnico previo, sobre un acuífero somero. Ante el sorpresivo brote de agua, la empresa "Quiero Casa" instaló una bomba de agua para evitar la anegación de la construcción, y comenzó a arrojar el agua por las coladeras. Frente a la indignación de los vecinos afectados cotidianamente por la falta de agua, la empresa construyó, durante una noche, un drenaje subterráneo por el que arroja a diario, directamente desde su terreno, 55 litros de agua por segundo. La respuesta vecinal fue la instalación de un plantón (campamento) para exigir la cancelación definitiva del proyecto.

La primera reacción del gobierno fue negar la existencia del acuífero y argumentar que el agua provenía de un drenaje fracturado por la empresa. Ante la rabia popular, el gobierno de la Ciudad suspendió la obra y la Procuraduría Ambiental y de Ordenamiento Territorial de la Ciudad de México, encargó a la Universidad Nacional Autónoma de México un estudio técnico que, después de unos meses, determinó que el agua provenía de un acuífero somero formado en el volcán Xitle, al sur de la ciudad. La empresa, que arrojó al menos 219 millones de litros de agua al drenaje durante un año, se comprometió a "resolver" el problema mediante la desviación del cauce natural de la corriente subterránea y a utilizar el acuífero para dotar de agua a las colonias aledañas. Por su parte, el gobierno autorizó la continuación del proyecto y el 5 de diciembre de 2016, envió un contingente de 400 granaderos para desmantelar el plantón vecinal. No obstante, ante el incumplimiento de la empresa y del gobierno, el plantón se reinstaló meses después y aún permanece la exigencia de la cancelación del proyecto (Ver “Desarrollos verticales" en Mapa 5).

Espiral 1(1): 023 - 028 | 023 


\subsection{El Nuevo Aeropuerto Internacional de la Ciudad de México (NAICM)}

Mientras el capital inmobiliario avanza sobre el núcleo urbano de la Ciudad de México, el presidente Enrique Peña Nieto (2012-2918) empleó todo el poder del gobierno federal para impulsar nuevamente el proyecto del aeropuerto. Una vez dividida la oposición ejidal en los alrededores de los restos del Lago de Texcoco, contrató al arquitecto Norman Foster, famoso por el diseño de varios rascacielos y de otros proyectos de aeropuertos en Londres, Hong Kong y Beijing, para diseñar el tercer aeropuerto más grande del mundo, cuya primera fase, que incluye las primeras tres pistas, costará más de 180 mil millones de pesos. Enseguida, logró la asociación de dos empresas mexicanas, ICA y Carso, de Carlos Slim, y dos empresas españolas, Acciona y FCC, para emprender la construcción del proyecto, además de la incorporación de una constelación de compañías internacionales encargadas del plan rector (Arup), el plan de negocios (Boston Consulting Group), el diseño logístico (NACO) y la coordinación del proyecto (Parsons International).

Además de las aeropistas, del edificio de la nueva terminal y de una zona de hangares (instalada sobre terrenos federales), el proyecto contempla la "Aerotrópolis", una ciudad compacta que incluye una zona industrial, una zona hotelera, centros comerciales, zonas de libre comercio y una zona de oficinas que detonará la especulación sobre las tierras ejidales de los pueblos aledaños. La barda perimetral del aeropuerto se ha extendido sobre 335 hectáreas ejidales de Santa Isabel Ixtapan, Nexquipayac y San Salvador Atenco para la construcción de la pista \#3. Por su parte, la autopista Pirámides-Texcoco y el tren de carga que permitirá trasladar el material necesario para la construcción de este mega-proyecto, han motivado la expropiación de otras 140 hectáreas de tierras ejidales.

En los alrededores del polígono que incluye el proyecto, la extracción de más de 4 millones de toneladas de tezontle está destruyendo decenas de cerros, algunos de los cuales son considerados sitios sagrados por sus pobladores, como los cerros Tezoyo y Tezoyuca. Por otro lado, se calcula que deben ser extraídas 2.4 millones de toneladas de tierra del polígono que ocuparán las pistas de aterrizaje, material que tendrá que ser depositado en diversos terrenos aledaños. Actualmente, el traslado del material se realiza mediante cuatrocientos camiones que transitan por los caminos ejidales locales; sin embargo, para acelerar el proceso se requiere la construcción de $13.5 \mathrm{~km}$ de ferrocarriles, por un monto de 459 millones de pesos que estará a cargo de Ferrovalle, una empresa subsidiaria de Kansas City Southern Mexico.

Pero más importante que el movimiento de tierras, el emplazamiento del proyecto del NAICM, implica la desecación definitiva del Lago de Texcoco con base en obras hidráulicas que permitan una gestión del agua a escala regional. La más importante de todas es el Túnel Emisor Oriente, un mega drenaje de 16 metros de diámetro y 62 $\mathrm{km}$ de longitud, diseñado para expulsar la mezcla de aguas pluviales de la cuenca de México y las aguas negras de la Ciudad de México, y concentrarlas en una planta de tratamiento en Atotonilco, Hidalgo. En contraparte, el proyecto requerirá 616 mil $\mathrm{m}^{3}$ de agua en su primera fase y 1.5 millones de $\mathrm{m}^{3}$ en su segunda fase, cifras que representan apenas el 31\% del agua que requerirá anualmente el NAICM. A esta cifra hay que añadir 23.6 millones de $\mathrm{m}^{3}$ de agua que serán necesarios para el funcionamiento de la Aerotrópolis, agua que deberá ser extraída de los manantiales de Texcoco (Ver "Proyecto nuevo aeropuerto" en Mapa 5) ${ }^{42}$.

\section{Conclusiones: discurso cartográfico crítico sobre el megaproyecto megalopolitano.}

La cartografía del tsunami inmobiliario permite visualizar y comprender la lógica espacial de la estrategia de apropiación capitalista del suelo urbano en la

$42 \mathrm{El}$ proyecto del nuevo aeropuerto fue cancelado en octubre de 2018 por el presidente electo Andrés Manuel López Obrador con el respaldo de una consulta ciudadana seriamente cuestionada por su metodología y por encontrarse "al margen de la ley". Sin embargo, a pesar de la cancelación formal del proyecto la construcción continuaba en enero de 2019.

024 | Espiral 1(1): 024 - 028 


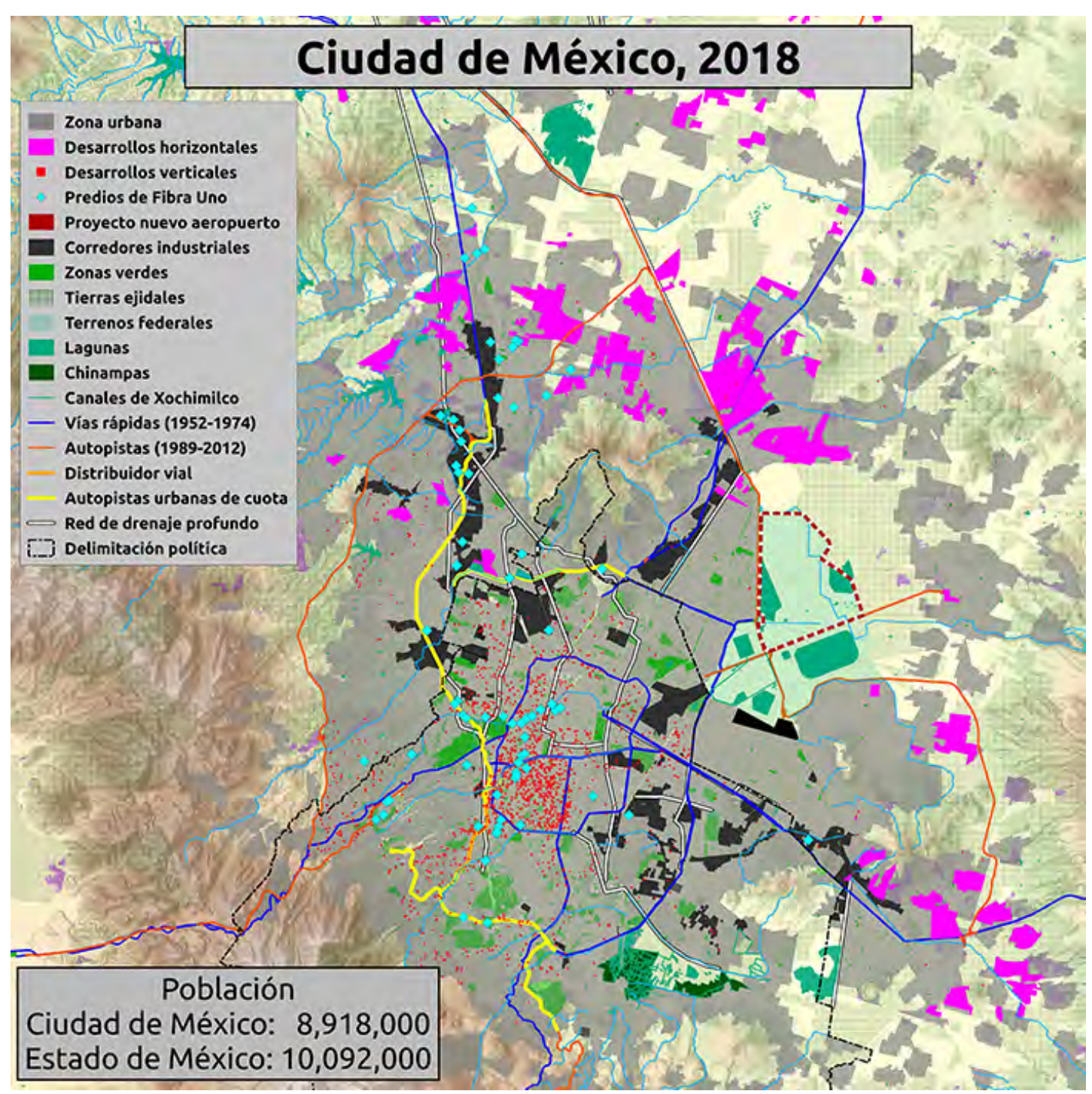

Mapa 5. Ciudad de México, 2018. Autor: Adrián Flores. Fecha de elaboración: septiembre, 2018

Fuentes: las capas utilizadas para este mapa se encuentran en la página geocomunes.org.

Ciudad de México. A partir de la cartografía de los ciclos de expansión urbana e industrial articulados por la red de infraestructura de transporte, este ejercicio posibilita el desarrollo de un discurso cartográfico crítico que, además de ofrecer una sistematización integral sobre el proceso de urbanización de la Ciudad de México, en términos territoriales e históricos, delinea los principales ejes que articulan el megaproyecto de la megalópolis en la Ciudad de México. Asimismo, contribuye a la articulación de la diversidad de resistencias que enfrentan la fase actual del proceso de urbanización salvaje en la Ciudad de México.

El discurso cartográfico crítico elaborado en torno del concepto del tsunami inmobiliario permite articular, por ejemplo, las resistencias contra los desalojos en el núcleo urbano que comúnmente se asocian con procesos de gentrificación, con las resistencias contra el despojo de tierras y agua en las zonas periféricas de la ciudad, como sucede con el proyecto del nuevo aeropuerto. De igual forma, permite integrar otros tipos de resistencia impulsados por clases medias en las zonas residenciales del núcleo urbano, donde no existen procesos de expulsión de población de bajos recursos por sectores de mayores ingresos, sino la destrucción del patrimonio histórico y arquitectónico de la ciudad. También visibiliza procesos de resistencia impulsados por sectores populares en zonas periféricas para contrarrestar la sobreexplotación de los acuíferos subterráneos de la ciudad. 
La cartografía del tsunami inmobiliario facilita la sistematización de información sobre los procesos de reducción de los espacios dedicados a la reproducción social y la expansión de los espacios dedicados a la producción de las ganancias. Uno de los elementos visuales más llamativos del discurso cartográfico es la reducción del sistema de lagos del valle de México (ver Mapa 1), frente a la expansión de tierras ejidales como resultado del segundo ciclo de expansión urbana (Ver Mapa 2). En el tercer ciclo comienza el proceso de expansión de zonas industriales y urbanas sobre las zonas ejidales cercanas al núcleo urbano (Ver Mapa 3), y en el cuarto ciclo, este proceso se expande hacia las periferias a partir de los ejes viales que articulan los corredores industriales (Ver Mapa 4).

Finalmente, se puede apuntar que un ejercicio cartográfico de esta naturaleza permite visualizar la lógica espacial del megaproyecto megalopolitano. Por ejemplo, el mapa de la quinta ola de urbanización, muestra cómo el tsunami inmobiliario simplemente reproduce los procesos de expansión inmobiliaria previos a una escala mayor y de manera articulada, en primer lugar, sobre las tierras ejidales del oriente y norte de la periferia urbana, y en segundo lugar sobre barrios asentados al sur y al poniente del núcleo urbano que delinea el primer anillo vial. La cartografía muestra que la tercera ola de expansión de infraestructura de transporte (representada en amarillo) ya ha sido completada en el poniente de la ciudad, y que su expansión hacia el oriente podría estar vinculada por el proyecto del nuevo aeropuerto.

La cartografía del tsunami inmobiliario muestra los avances preliminares de un proyecto que todavía requiere afinar distintos procesos espaciales: 1) la transformación de las haciendas y ranchos en propiedad social de la tierra; 2) los proyectos superficiales y subterráneos para la desecación del sistema de lagos y la gestión del agua de la cuenca de México; 3) la articulación entre los corredores industriales, los proyectos inmobiliarios públicos y privados sobre las tierras ejidales y a lo largo de los ejes viales; 4) la desarticulación de los sistemas agroecológicos que subsisten en Xochimilco y Texcoco; y finalmente 5) la lógica espacial de la estrategia de apropiación del suelo urbano por parte de las distintas empresas inmobiliarias y los mecanismos financieros y políticos que lo hacen posible. Este ejercicio cartográfico todavía debe ser complementado con el mapeo del cártel inmobiliario.

Durante los últimos dos años, la investigación cartográfica de estos cinco elementos ha avanzado de manera paralela y coordinada con los ritmos y necesidades del movimiento urbano popular en la ciudad de México. Es en este acompañamiento que se retoma el concepto de tsunami inmobiliario para articular estos esfuerzos en un sólo discurso cartográfico que ha sido construido, discutido y presentado en diversos foros y reuniones vecinales organizados para enfrentar el proceso que la misma cartografía describe, con el objetivo de contribuir a fortalecer la coherencia que los procesos de resistencia han adquirido en los últimos treinta años.

\section{Bibliografía}

Aeropuerto Internacional de la Ciudad de México. 2015. Breve historia. Antecedentes históricos. https://www.aicm.com.mx/aicm/acerca-del-aicm/breve-historia

Archivo Historico del Distrito Federal. No. 80. AHDF, Planoteca. Título: Original Plano de Iztapalapa mostrando el Canal Nacional. Año: S/F. Medidas: 107cm x 105cm. Clasificación original: Planero horizontal A-5, fajilla 33, clasif.: 401(073) /240(2) Ubicación Topográfica: Módulo 8, Planero 5. http://www.patrimonio.cdmx.gob.mx/archivo-historico/ Doumentos\%20digitalizados/Mapas.html

Archivo Historico del Distrito Federal. No. 81. AHDF, Planoteca. Título: Plano General de la Ciudad de México. Compañía de Luz y Fuerza. Verdana. Esc.: 1:100. Año: S/F. Medidas: $141 \mathrm{~cm}$ x 88cm. Clasificación original: Planero horizontal B-1, fajilla 43, clasif.: 401 (073) 249 Ubicación Topográfica: Módulo 8, Planero 5. http://www.patrimonio.cdmx.gob.mx/ archivo-historico/Doumentos\%20digitalizados/Mapas.html

026 | Espiral 1(1): 026 - 028 
Barreda Andrés, 2009. Crisis de urbanización no sostenible en la corona de ciudades, pueblos y municipios que rodean a la Ciudad de México. México: Unión de Científicos Comprometidos con la Sociedad (UCCS).

Bassols Mario y Espinosa Maribel. 2011. Construcción social del espacio urbano: Ecatepec y Nezahualcóyotl. Dos gigantes del oriente. En Polis, vol. 7, núm. 2, pp. 181-212.

Centro de Análisis Multidisciplinario. 2015. México: Esclavitud moderna. Cae 78.1\% el poder adquisitivo. Reporte de investigación 120. UNAM. https://cam.economia.unam. $\mathrm{mx} /$ reporte-de-investigacion-120-mexico-esclavitud-moderna-cae-78-71-el-poderadquisitivo/

Casasola Zapata Gustavo. 1992. Historia Gráfica de la Revolución Mexicana 1900 - 1970. México: Trillas, pág. 2.738

Batres Lenia. 2017. El bando dos y la vivienda popular vs la ciudad de lujo y la rapiña inmobiliaria. En Sin Embargo. Octubre 30, 2017

DOF: 27/06/1980. Decreto por el que se expropia por causa de utilidad pública una superficie de 0-64-01 Has., en favor de la Comisión Federal de Electricidad, ubicada en el ejido denominado Peñón de los Baños, perteneciente al Municipio de San Miguel de Allende, Gto. (Registrado con el número 10871). México: Diario Oficial de la Federación. http://dof.gob.mx/nota_detalle. php?codigo $=4855726 \&$ fecha $=27 / 06 / 1980 \&$ print $=$ true

Echeve1rría, Bolívar. 2013. Modelos elementales de la contradicción campo-ciudad. México: Itaca.

Flores, Adrián 2007. Poder en el espacio rural. Estudio del poder en el espacio rural y la subordinación al poder urbano. Reflexiones a partir de la zona de Cofre de Perote en la segunda mitad del siglo XX. Tesis de Licenciatura. Facultad de Filosofía y Letras. Colegio de Geografía, UNAM.

Garza, Gustavo. 1985. El proceso de industrialización en la Ciudad de México (1821-1970). México: El Colegio de México.

Garza Gustavo y Schteingart Martha. 1984. Ciudad de México: dinámica industrial y estructuración del espacio en una metrópoli semiperiférica. En Demografía y Economía, Volumen XVIII: 4. México: El Colegio de México

Hernández, Genera. 2016. Transiciones productivas entre el nuevo orden megalopolitano y el viejo desorden urbano: caso Azcapotzalco 1986-2015. Serie (IV-3B). Congreso Internacional CONTESTED_CITIES, Eje 3: Desplazamiento WPCC-163517 http://contested-cities.net/ working-papers/autor/genaro-hernandez-camacho/

Instituto Nacional de Estadística y Geografía (México). 1994. Estadísticas históricas de México 2009. Instituto Nacional de Estadística y Geografía. México: INEGI.

Instituto Nacional de Estadística y Geografía (México). 2009. Estadísticas históricas de México 2009. Instituto Nacional de Estadística y Geografía. México: INEGI.

Instituto Nacional de Estadística y Geografía (México). 2015. Estadísticas históricas de México 2014. Instituto Nacional de Estadística y Geografía. México: INEGI.

Janoschka, M. \& J. Sequera. 2014. Procesos de gentrificación y desplazamiento en América Latina, una perspectiva comparativista en Desafíos metropolitanos. Un diálogo entre Europa y América Latina, Juan José Michelini (ed.), pp. 82-104. Catarata. Madrid. ISBN: 978-848319-887-2

Jiménez, C., Dávila, D. y Trejo, R. 2012. Expropiaron en 1952 y aún no les indemnizan. Crónica. http://www.cronica.com.mx/notas/2002/24242.html

Macías, María Carmen y Pérez María de Montserrat. 2015. La propiedad agraria durante la era porfiriana. México: UNAM-IIJ

Monsivais, C. 2005. No sin nosotros. Los dias del terremoto 1985-2005. Mexico: Ediciones Era.

United Nations, Department of Economic and Social Affairs, Population Division (2018). World Urbanization Prospects: The 2018 Revision, Online Edition. https://esa.un.org/unpd/ wup/Download/

Padilla Díaz de León, Guillermo. 1982. Tlalnepantla, Tierra de en medio. México: H. Ayuntamiento de Tlalnepantla de Baz, Edo. Mex. 
Peralta, Araceli. 2009. El canal, puente y garita de La Viga. En Long J. y Attolini A. (Coords.) Caminos y mercados de México. México: INAH/IIH-UNAM.

Pradilla Cobos Emilio. 2016. Zona metropolitana del valle de México: neoliberalismo y contradicciones urbanas. En Sociología, año 18, nº 42, p. 54-89. Porto Alegre.

Schteingart Martha. 1987. Expansión urbana, conflictos sociales y deterioro ambiental en la ciudad de México. El caso del Ajusco. En Estudios Demográficos y Urbanos, Vol. 2, Num. 3. Mexico: El Colegio de México.

Schteingart Martha. 1983. La promoción inmobiliaria en el área metropolitana de la Ciudad de México (1960-1980). En Demografía y Economía, XVIII: 1. México: El Colegio de México.

Secretaría de Economía (México). 1956. Estadísticas sociales del porfiriato. 1877-1910. Dirección General de Estadística. México: DGE.

Villanueva, Minerva. 1990. Obreros urbanos: pasado social e incorporación a la industria. México: CIESAS.

Zurita, Elio. 2007. Decreto presidencial relativo al IETU. En Excelsior online, 12 de noviembre de 2007. https://www.ccpm.org.mx/avisos/Decreto\%20presidencial\%20relativo\%20al\%20 IETU.pdf 